\title{
Using Facebook as a Collaborative and Communicative Tool
}

\section{Arumugam Raman}

Universiti Utara Malaysia

arumugam@uum.edu.my

Habibah Lateh

Universiti Sains Malaysia

habibah@usm.my

\section{Doi:10.5901/mjss.2015.v6n1s1p286}

\begin{abstract}
This study discusses the acceptance of the utilisation of Facebook as a communication tool and collaborative educational tool amongst secondary school students in the district of Kulim, Kedah, Malaysia. This study is based on the five constructs of the Unified Theory of Acceptance and Use of Technology (UTAUT) model proposed by Venkatesh, Morris, Davis and Davis (2003). These five constructs are performance expectancy, effort expectancy, social influence, facilitating conditions and behavioral intentions. The respondents for this study were 210 secondary school students who were randomly selected in the Kulim district. The data for this study was elicited through questionnaires adapted from Venkatesh et al. (2003). The data were analyzed using the Statistical Package for the Social Science (SPSS) and Partial Least Squares (SmartPLS). The results showed that performance expectations (PE) $(\beta=-0.018, p>0.01)$, effort expectations (EE) $(\beta=0.242, p>0.01)$ facilitating conditions (FC) $(\beta=0.330, p>0.01$ and for social influence $(S I)(\beta=0.260, p>0.01)$ do not have a significant positive impact on behavioral intentions $(B I)$. The value for $R 2=0.532$ indicates that $53.2 \%$ of the variance in the use of Facebook applications for communication and collaboration can be explained by the BI. The study also revealed that the either PE, EE, SI or FC showed a significant correlation with the BI. These findings have an important implication for the development of education. The use of Facebook applications and other social media as a medium for collaboration and communication in the classroom could not promote quality teaching and learning. This study only examines the four constructs of the UTAUT model proposed by Venkatesh et al. (2003). However, given the model's robustness in predicting user acceptance of technology, it is recommended that future studies look at different constructs such as attitudes and motivation, and also examine the moderating effects of age and sex on the BI and Use Behavior.
\end{abstract}

Keywords: Facebook, UTAUT model, Education, Malaysia;

\section{Introduction}

Although Facebook is widely accepted and used by school-aged users for communication, its potential in the classroom for teaching and learning purposes is still very much debated in Malaysia. Teachers are hesitant of promoting the use of Facebook in the classroom, although it has been argued that social networking sites like Facebook have the ability to encourage communication and collaboration skills of students (Maloney, 2007). It has been argued that social networking sites allow learners to create new networks based on their interests that may indirectly help with developing the communication skills as well as acquisition and creation of new knowledge (Selwyn, 2009). Teachers and educators are usually concerned with the negative effects of using sites such as Facebook that is deemed to be a social site which is usually used for leisure activities. Although there have been studies which have showed the positive effects of social networking sites on student performance, there seems to be a lingering concern of the adverse effects on student performance and literacy skills. Taking all these into account, this study explores the level of acceptance of Facebook among students in the rural district in Malaysia. Using the UTAUT model, the purpose of this study, among others, is to elicit feedback on students' level of acceptance of applications available in Facebook as tools to communicate and collaborate with classmates and teachers outside school. This will help identify willingness and patterns of student learning outside the classroom and integrating Facebook in teaching and learning may improve their performance in critical subjects like English, Mathematics, Science and History. 


\subsection{Objectives of the study}

The main objectives of this study are:

i) To measure the relationship between Performance Expectation with Behavioral Intention.

ii) To measure the relationship between Effort Expectancy with Behavioral Intention.

iii) To measure the relationship between Social Influence with Behavioral Intention.

iv) To measure the relationship between Facilitating Conditions with Behavioral Intention.

\section{Literature Review}

We mainly focus on the importance of Facebook in education and carried out surface analysis of previous researches. We found limited evidence to conduct comparative analysis on the usage of Facebook in school setting.

\subsection{The use of Facebook in education}

There are many advantages of using social networking sites like Facebook. These sites are not merely for entertainment and communication. A study was done by the National School Boards Association (of America) in 2007, shows that there is a positive correlation between the use of Facebook and students' performance. The study showed that students involved in social networks had both traditional as well as 21st century skills including communication, creativity, collaboration and leadership. Social networking sites allow students to acquire skills that are important and relevant in the digital era.

By integrating the use of social networking sites and the Internet in the teaching and learning process, the role of teachers is transformed from helping students learn in the physical classroom to being a mentor and information provider in terms of helping students plan advanced learning, planning careers and providing extra educational resources available on the Internet (Podoll \& Randall, 2005). The study by DuBois et al. (2002) has shown that frequent communication between mentor and teenage mentees increases exponentially the effectiveness of the mentoring programme. Thus, Facebook can create communication opportunities for discussion between teachers and students.

Voithofer (2007) states that the teaching and learning of specific skills related to educational technology can help students assess the technical and pedagogical features of educational technology, the social aspects of educational technology, and how to keep up with advancements in technology. Thus, it is essential for teachers to introduce students to social networking sites and how to optimize the use of these sites to enhance the learning experience. Teachers can provide additional training for students to open a Facebook account and invite students into the Facebook pages. Teachers can post learning-related posts, homework, as well train students to further enhance their skills in using the Facebook as a teaching and learning tool. Students can also be invited to post messages related to their lessons or things that are related to what they are learning in class. Attempts at integrating the use of technology, especially Facebook that is particularly popular with students will be appreciated by students (Arumugam, 2014).

\subsection{Unified Theory of Acceptance and Use of Technology (UTAUT)}

The Unified Theory of Acceptance and Use of Technology (UTAUT) is a technology acceptance model developed by Venkatesh et al. (2003). This model explains how the intentions and behavior of consumers in the use of a technology is influenced by factors such as performance expectancy (PE), effort expectancy (EE), social influence (SI) and facilitating condition (FC) (Figure 1). There are four factors that have been documented that could affect the influence of these factors. 


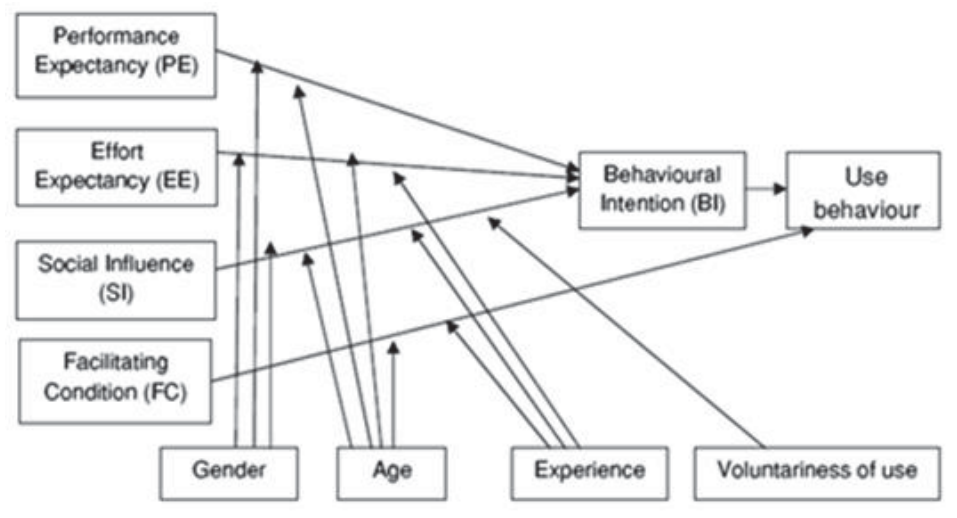

Figure 1: UTAUT Model by Venkatesh et al. (2003)

Performance Expectancy (PE) is defined as the level of belief that an individual has about the use of a system or new technology that can improve work performance. Effort expectancy $(E E)$ is defined as the level of ease an individual uses a system or new technology. Social Influence (SI) is defined as the extent to which an individual feels that other people important to him/her believe that they should use a system or new technology. Facilitating Conditions (FC) is defined as the perceived level of existence of organizational and technical infrastructure to support a system/new technology.

There have been many studies done about the use of social networking sites and other relevant technology for learning purposes. These studies use the UTAUT model as a basis for their studies. Among these, is a study done by Bens and Mario (2012) which examined students' acceptance of blogs. Bens and Mario (2012) used the UTAUT model with eight constructs to determine students' acceptance of blogs in learning. This study found that two of the constructs in the UTAUT model, i.e. SI and PE showed a significant relationship with BI. In addition, another related study using the UTAUT model was carried out by Bashar (2012) from the Swedish Business, Örebro University. The study used the UTAUT model to examine the level of acceptance of social media in Egypt. Bashar (2001) identified that one of the factors that drove the adoption of social media was Facebook. This study used the UTAUT model based on the five constructs of PE, EE, SI, FC and BI. The findings showed that $\mathrm{SI}$ and EE have a positive significant impact on BI. However, Sedana and Wijaya (2009) in their study on the application of the UTAUT model, found that PE had a positive and significant correlation ( $p$-value $<0.01$ ) with BI. Debashish and Robert (2012) found in their study that the PE and EE did not have a significant influence on the BI.

\subsubsection{The proposed model by the researchers}

In this study, the researchers maintain the original UTAUT model but with a slight reduction to the moderators. This is done to suit the study as well as the constraints of time and cost to run the study. For this study, the constructs used are Performance Expectancy (PE), Effort Expectancy (EE), Social Influence (SI), Facilitating Conditions (FC) and Behavioral Intention (BI). Therefore, the constructs that were dropped from this study include use behavior, gender, age, experience and voluntariness of use. The figure below shows the model used in this study.

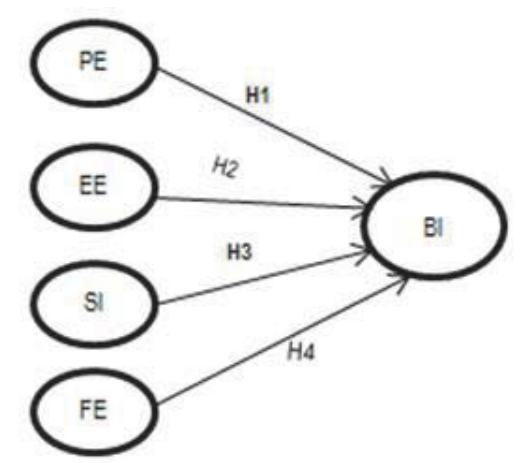

Figure 2: Proposed model 
The hypotheses of the study are:

H01: Performance Expectation has a significant positive relationship with Behavioral Intention.

Ho2: Effort Expectancy has a significant positive relationship with Behavioral Intention.

Ho3: Social Influence has a positive significant relationship with Behavioral Intention.

Ho4: Facilitating conditions has a positive significant relationship with Behavioral Intention.

\section{Methodology}

This is a quantitative study. This study adopted items based on the variables in the UTAUT model developed by Venkatesh (2003). A questionnaire was developed based on the elements of the UTAUT model by Venkatesh et al. (2003). The questionnaire consists of six sections with 22 questions. The section to gather demographic data consisted of three questions designed to gather personal information of the respondents such as gender, level of secondary education and the duration of use of Facebook. The second section consisted of four questions designed to obtain information about performance expectancy. These constructs were intended to obtain information of the usage of Facebook to help students with their schoolwork. The third section contains four questions which intended to obtain information about effort expectancy. This section intends to identify the skills of the students in using Facebook applications. The fourth part containing four questions was designed to obtain information about Social Influence. This section intends to identify the people around the students who influence them to use Facebook applications. The sample consisted of 210 secondary school students from Kulim, Kedah. The questionnaires were distributed to these students to determine their views on the use of Facebook applications for communication and collaboration in their learning processes. The reliability and validity of the items in the questionnaire were determined using the SmartPLS software. An item that had a loading value of $(\lambda)<$ 0.5 was dropped because it would measure the same thing as other items. For this study, two items PE4 and FC3 have loadings $(\lambda)$ that was $<0.5$, thus the item was removed before further analysis was carried out.

\section{Data Analysis}

Table 1 shows the composition of the respondents for this study. The study involved 210 students in three schools in Kulim, Kedah. On average, $42.86 \%$ or 90 of the total respondents were males and $57.14 \%$ or 120 were females.

Table 1: Gender

\begin{tabular}{lcc}
\hline Gender & Frequency & Percentage \% \\
\hline Male & 90 & 42.86 \\
Female & 120 & 57.14 \\
Total & 210 & 100.00 \\
\hline
\end{tabular}

Table 2 shows that $45.23 \%$ or 95 of the respondents have been using Facebook for less than one year and $54.76 \%$ or 115 of the respondents have been using Facebook for more than a year.

Table 2: Duration of Use of Facebook

\begin{tabular}{lcc}
\hline Duration & Frequency & Percentage \% \\
\hline Less than 1 year & 95 & 45.23 \\
More than 1 year & 115 & 54.76 \\
Total & 210 & 100.0 \\
\hline
\end{tabular}

Most of the items used in this study have been confirmed by Venkatesh et al. (2003). However, the items were reviewed in terms of reliability and validity. This was evaluated through reliability (cronbach alpha), composite reliability, convergent and discriminant validity.

\subsection{Reliability of constructs}

An instrument is said to have a high internal value when the reliability of Cronbach Alpha is more than 0.8 and not less than 0.6 (Henseler et al., 2009; Nunnally \& Bernstein, 1994). The results of this study showed that the four constructs 
studied here had a Cronbach Alpha value of more than 0.8, while one construct had an Alpha value above 0.7. The detailed analysis of the results is shown in the table 3 below.

Table 3: Cronbach alpha

\begin{tabular}{lc}
\hline Constructs & Cronbach Alpha (a) \\
\hline Behavioral Intention & 0.947 \\
Effort Expectancy & 0.909 \\
Facilitating Conditions & 0.865 \\
Performance Expectancy & 0.799 \\
Social Influence & 0.953 \\
\hline
\end{tabular}

\subsection{Convergent validity}

An assessment of the convergent validity shows that the test concept is closely related to other tests designed to measure the same theoretical concept. Convergent validity ensures that items that are constructed measure the construct that it is supposed to measure. Fornell and Larcker (1981) suggest the average variance extracted (AVE), the composite reliability (CR) of each construct and the validity of each construct will be able to measure convergent validity. The value of each AVE should be more than 0.50 indicates that the difference of $50 \%$ of the items, thus indicating adequate convergent validity. The reliability of the items are measured by loading factor and cross loading factor.

The value of cross loadings in Table 4 shows that all items are in the range of 0.7 to 0.9 . This exceeds the value ( $>0.5$ ) suggested by Hair et al. (2006) and is deemed to have a significant cross loading. In addition, we can see from the table that each item has a value higher for all the defined constructs. The CR for each construct is assessed using the Cronbach Alpha (a). Table 4 shows a summary of the reliability of the composite which is above the recommended value of 0.7 (Hair et al ., 2010). Results show that all eight constructs have valid measures and are in the range recommended by Hair (2010).

Table 4: Results of the Measurement Model

\begin{tabular}{lcccc}
\hline Constructs & Items & Loadings & AVE & CR \\
\hline Performance Expectancy & PE1 & 0.94 & 0.90 & 0.97 \\
& PE2 & 0.95 & & \\
& PE3 & 0.96 & & \\
& PE4 & dropped & & \\
Effort Expectancy & EE1 & 0.91 & 0.78 & 0.94 \\
& EE2 & 0.93 & & \\
& EE3 & 0.87 & & \\
Social Influence & EE4 & 0.82 & & \\
& SI1 & 0.91 & 0.71 & 0.91 \\
& SI2 & 0.86 & & \\
Facilitating Conditions & SI3 & 0.83 & & \\
& SI4 & 0.77 & & \\
& FC1 & 0.92 & 0.72 & 0.88 \\
& FC2 & 0.86 & & \\
Behavioral Intention & FC3 & dropped & & \\
& FC4 & 0.75 & & \\
& BI1 & 0.95 & 0.92 & 0.97 \\
& BI2 & 0.95 & & \\
\hline
\end{tabular}

\subsection{Discriminant validity}

Discriminant validity is assessed to calculate the different levels of constructs. It examines whether constructs unintentionally measure something else. According to Fornall et al. (1982), discriminant validity tests whether concepts or measurements that are supposed to be related are, in fact, unrelated. Discriminant validity is achieved if the square AVE (BOLD) is higher than the correlation between the constructs. In Table 5 below, the value of the AVE in bold is greater 
than the other constructs subsumed in it.

Table 5: Construct correlation matrix

\begin{tabular}{cccccc}
\hline & PE & EE & SI & FC & BI \\
\hline PE & 0.956 & & & & \\
EE & 0.653 & 0.886 & & & \\
SI & 0.454 & 0.652 & 0.844 & & \\
FC & 0.590 & 0.760 & 0.647 & 0.846 & \\
BI & 0.453 & 0.650 & 0.623 & 0.671 & 0.956 \\
\hline
\end{tabular}

+Diagonal: square root of the average variance extracted from the observed variable (item)

*Off-Diagonal: correlation between constructs

\section{Testing of the Proposed Model}

Table 6 shows the path coefficient. The $R^{2}$ for each construct (latent variable) shows differences in the level of cooperation that can be explained. The results showed that Performance Expectation (PE) $(\beta=-0.018, p>0.01)$, Effort Expectation (EE) $(\beta=0.242, p>0.01)$, Social Influence (SI) $(\beta=0.260, p>0.01)$, and Facilitating Conditions (FC) $(\beta=$ $0.330, p>0.01)$. Therefore PE, EE, SI and FC do not have significant positive impact on BI. All the hypotheses are not supported in this study because the $\mathrm{R}^{2}=0.532$ indicates that $53.2 \%$ of the variance in Behavioral Intention can be explained by the extent of PE, EE, SI, and FC. These results are different to findings by Bens Pardamean and Mario Susanto (2012) as well as Bashar Salim (2012), where they also found one of the constructs of Social Influence (SI ) had a significant relationship with the BI. The results for the current study can be viewed in Figure 7.

Table 6: Regression analysis

\begin{tabular}{ccccl}
\hline Hypothesis & Relationship & Coefficient $(\boldsymbol{\beta})$ & t value & Results \\
\hline H1 & PE-BI & -0.018 & 0.192 & Not accepted \\
H2 & EE-BI & 0.242 & 1.662 & Not accepted \\
H3 & SI-BI & 0.260 & 1.922 & Not Accepted \\
H4 & FC-BI & 0.330 & 1.640 & Not Accepted \\
\hline
\end{tabular}

\section{Discussion}

This study not supports the findings of previous studies in which independent variables i.e. PE, EE, SI, and FC influence $\mathrm{BI}$. This study also showed how BI could not predict the use of Facebook applications for learning and communication purposes. Despite the use of Facebook applications as a medium for communication and learning is one of the best methods for adapting education in this day and age but the proposed model not supporting the claim. However more studies needed to determined the use of UTAUT model in education setting. We cannot deny that in an increasingly digital and technological based world, teachers can no longer rely solely on traditional teaching where students may easily get bored and disengaged. Now, students are no longer as students in the past where students would listen and write only to receive information. Students now prefer to explore and find out things on their own and not just listen to what the teacher says. Therefore more constructs should be identified by furture researchers to measure the impact of particular construct towards BI. This study also contradicted with another research conducted by Arumugam et al (2014). Although the study conducted in the same country however the findings are totally different. It is expected the location plays important role in such findings.

Facebook applications pertaining to applications that are related to teaching and learning should be explored and added, so that the use of the applications can be integrated into classroom teaching and learning activities. Many educators and parents extol the detrimental effects of Facebook applications. This is mostly due to the lack of real understanding of the advantages that can be gained by students when using Facebook for communication and learning. Parents and teachers need to be aware of the various other functions and uses of Facebook that can be exploited to benefit and enrich the teaching and learning context.

The findings of this study provide insights into the use of Facebook applications for communication and learning of high school students. In order to make the findings more relevant, teachers and school administrators suggested that the study should be expanded to also include teachers and parents. This will make the study more extensive and the views of 
each individual in relation to education will be obtained.

This study only concentrated on four constructs of the UTAUT model founded by Venkatesh et al. (2003). Therefore, it is recommended that future studies add more constructs such as attitudes and motivation as well as the moderating effects of age and gender on the BI and Use Behavior. Since the study was limited to secondary school students, it is proposed that a study of this nature be carried across the board with a larger sample size in order to get a clearer picture of the patterns of use of information technology among teachers, students and parents. The Government should try to improve the existing facilities related to information technology in schools, so that students can use the facilities optimally. The attitude of being apprehensive of technology should be cast aside. The integration of information technology in the classroom is essential in order to stay relevant in this digital age. Learners today are digital learners and they are comfortable with using the technology. Integrating Facebook in the teaching and learning process may improve our educational standards worldwide as well as create $21^{\text {st }}$ century learners that are skillful in handling information technology.

\section{References}

Arumugam, R., Ruuhina, S., \& Paramjit (2014). Facebook as a collaborative and comminication tool: A study of a secondary school students in Malaysia.Paper presented at the International Conference on Communication and Media 2014 (i-Come 2014), Langkawi, Kedah, Malaysia

Bashar S. (2012). An Application of UTAUT Model for Acceptance of Social Media in Egypt: A Statistical Study, Swedish Business School, Örebro University, 2012, International Journal of Information Science, 2(6): 92-105

Bens P. \& Mario, S. (2012). Assessing User Acceptance toward blog technology using the UTAUT Model. International Journal Of Mathematics And Computers In Simulation, 1(6), 203-2012.

Debashish M. and Robert, J.M. (2012). Extending Utaut To Explain Social Media Adoption by Microbusinesses, International Journal of Managing Information Technology (IJMIT), 4(4)

Dubois, D. L., Holloway, B. E., Valentine, J. C., \& Harris, C. (2002). Effectiveness of mentoring programs for youth: A meta-analytic review. [Special Issue]. American Journal of Community Psychology,30(2), 157-197.

Fornell, C., \& Larcker, D. F. (1981). Evaluating structural equation models with unobservable variables andmeasurement error. Journal 0 f Marketing Research, 48, 39-50.

Hair, J. F., Ringle, C. M., \& Sarstedt, M. (2011). PLS-SEM: Indeed a silver bullet. The Journal of Marketing Theory and Practice, 19(2), 139-152.

Hair, J. F., Sarstedt, M., Ringle, C. M., \& Mena, J. A. (2012). An assessment of the use of partial least squares structural equation modeling in marketing research. Journal of the Academy of Marketing Science, 40(3), 414-433.

Hair, J. F., Sarstedt, M., Pieper, T. M., \& Ringle, C. M. (2012). The use of partial least squares structural equation modeling in strategic management research: a review of past practices and recommendations for future applications. Long range planning, 45(5), 320340.

Henseler, J., Ringle, C.M., \& Sinkovics, R.R. (2009). The use of the partial least squares path modeling in international marketing. New Challenges to International Marketing. Advances in International Marketing, 20, 277-319.

Maloney, E. (2007). What Web 2.0 can teach us about learning? Chronicle of Higher Education, 53Nunnally, J. C., \& Bernstein, I. H. (1994). Psychometric Theory (3) McGraw-Hill. New York.

Nunnally, J. C., \& Bernstein, I. H. (1994). Psychometric theory (3rd ed.). New York: McGrawHill.

Podoll, S., \& Randle, D. (2005). Building a virtual high school...click by click. T.H.E.Journal, 33(2), 14-19.

Ringle, C. M., Wende, S., \& Will, A. (2005). SmartPLS 2.0 M3, Available at http:// www.smartpls.de.

Sedana, IGN., dan Wijaya, W., (2010), UTAUT Model for Understanding Learning Management System. Internetworking. 2(2).

Selwyn, N. (2009). Faceworking: Exploring Students' Education-Related Use of "Facebook". Learning, Media andTechnology, 34(2), 157-174

Venkatesh, M.G. Morris, G.B. Davis, F.D. Davis, (2003). User acceptance of information technology: toward a unified view, "MIS Quarterly, 27, pp. 425-478, 2003.

Voithofer, R.J., (2007). Studying Intertextuality, Discourse, and Narratives to Conceptualize and Contextualize Online Learning Environments in M. Orey, V. J. McClendon, \& R. M. Branch (Eds). Educational Media and Technology Yearbook: Volume 32, 2007. 